\title{
Neuroendocrine tumor presenting like lymphoma: a case report
}

\author{
Riccardo Del Vescovo ${ }^{1 *}$, Roberto Luigi Cazzato', Sofia Battisti ${ }^{1}$, Francesco D’Agostino ${ }^{1}$, Bruno Vincenzi ${ }^{2}$, \\ Rosario Francesco Grasso ${ }^{1}$ and Bruno Beomonte Zobel ${ }^{1}$
}

\begin{abstract}
Introduction: Neuroendocrine tumors are a rare but diverse group of malignancies that arise in a wide range of organ systems, including the mediastinum. Differential diagnosis includes other masses arising in the middle mediastinum such as lymphoma, pericardial, bronchogenic and enteric cysts, metastatic tumors, xanthogranuloma, systemic granuloma, diaphragmatic hernia, meningocele and paravertebral abscess.
\end{abstract}

Case presentation: We present a case of 42-year-old Caucasian man with a neuroendocrine tumor of the middleposterior mediastinum and liver metastases, which resembled a lymphoma on magnetic resonance imaging.

Conclusion: The differential diagnosis in patients with mediastinal masses and liver lesions should include neuroendocrine tumor.

\section{Introduction}

Neuroendocrine tumors (NETs) are a rare but diverse group of malignancies that arise in a wide range of organ systems. This can therefore include the mediastinum $[1,2]$.

Differential diagnosis includes other masses arising in the middle and posterior mediastinum, such as lymphoma, pericardial, bronchogenic and enteric cysts, metastatic tumors, xanthogranuloma, systemic granuloma, diaphragmatic hernia, meningocele and paravertebral abscess. When a large mass is discovered, pathological conditions of the anterior mediastinum, such as thymoma, germ cell tumors, intrathoracic goiter, lipoma, lymphangioma and aortic aneurysm, should also be considered $[3,4]$. We present a case of a NET of the middle-posterior mediastinum with liver metastases, which resembled a lymphoma on magnetic resonance imaging (MRI).

\section{Case presentation}

A 42-year-old Caucasian man was referred to our institution because of a recent onset of dysphonia. He had no significant past medical history and his physical examination was unremarkable. His erythrocyte

\footnotetext{
* Correspondence: r.delvescovo@unicampus.it

'Department of Radiology, Campus Bio-Medico, University of Rome, Italy Full list of author information is available at the end of the article
}

sedimentation rate was increased $(38 \mathrm{~mm} / \mathrm{h}$; normal range 0.00 to $17.00 \mathrm{~mm} / \mathrm{h}$ ). His blood cell count was normal as were the results of his other laboratory tests, including human immunodeficiency virus serology, urea and electrolytes, liver function tests and lactate dehydrogenase levels. Chorionic gonadotropin, neuron-specific enolase (NSE), prostate specific antigen, carcinoembryonic antigen, cancer antigen-125 and cancer antigen-19.9 were also tested and found to be negative. A noncontrast and postcontrast MRI of his mediastinum revealed a $6 \mathrm{~cm} \times 4 \mathrm{~cm} \times 5 \mathrm{~cm}$ solid lesion in the left paratracheal area, which appeared to enter and widen the aortopulmonary space. It also displaced his distal trachea and branches of his left bronchus medially and inferiorly, respectively. On T2-weighted images, the mass showed homogeneous high signal intensity. In contrast, a low intensity signal was noted on T1-weighted images and on the apparent diffusion coefficient (ADC) map when diffusion weighted images (DWI) were considered (Figure 1). The postcontrast T1-weighted images showed poor enhancement within the solid lesion (Figure 2). No lymph node involvement was noted in other areas of his chest. The MRI was then extended to his abdomen and showed some solid lesions in the II, III and VIII hepatic segments. These had the same patterns of signal intensity observed in the mediastinal mass on the T1- and T2-weighted images, before and after

\section{Biomed Central}




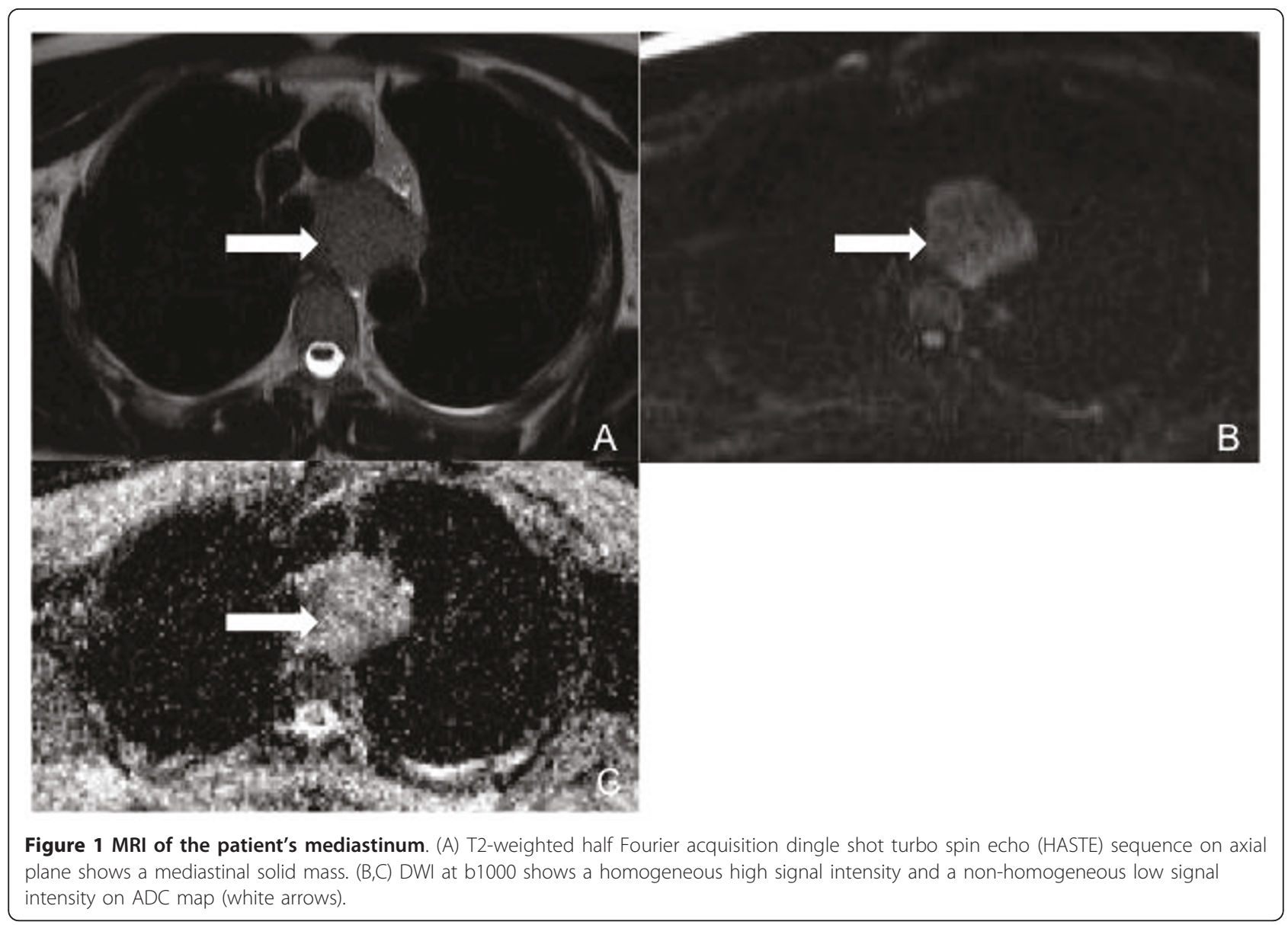

administration of contrast medium (Figures 3 and 4). No vascular or biliary structures were invaded by the hepatic mass and no abdominal lymph node involvement was noted.

According to the radiological features, the diagnosis was suspected lymphoma. Therefore, bioptical sampling of the hepatic lesion was performed (Precisa: $18 \mathrm{G} \times 2$ $\mathrm{cm})$. Microscopic examination revealed small sized cells, some of them spindle-shaped, which were positive for cytokeratins AE1/AE3, chromogranin, NSE and synaptophysin on immunohistochemical analysis. Ten percent of the cells expressed Ki67 and none of them showed a CD3-CD20 pattern. According to the pathological response, the diagnosis was a NET with hepatic metastasis.

Systemic chemotherapy based on cisplatin plus etoposide was started and then replaced by a new scheme based on capecitabine because of the progression of the disease, which was particularly noticeable in his liver. Therefore, a transarterial chemoembolization was considered as a suitable option to control the hepatic disease and then performed by emulsifying polyvinyl alcohol particles and doxorubicin [5].

\section{Discussion}

NETs are a rare but diverse group of malignancies that arise in a wide range of organ systems. Gut-derived NETs arise from the diffuse endocrine system and, according to the 2002 World Health Organization classification system [6], are most simply classified based on their site of origin as either 'functional' (symptomatic hormone secretion) or 'non-functional' (no symptomatic hormones). Many investigators still find it practical to use the categorization of NETs based on the embryologic origin into foregut tumors (bronchi, stomach, pancreas, gallbladder, duodenum), midgut tumors (jejunum, ileum, appendix, right colon), and hindgut tumors (left colon, rectum). Although there has been continued improvement in detection, NETs (most commonly, midgut NETs) have frequently metastasized to the liver by the time of diagnosis. A diverse range of imaging modalities can be used for the assessment of NETs.

The case presented here was a suspected malignant mediastinal tumor, because of the young age of our patient and the presence of dysphonia. For this reason, MRI was also extended to his abdomen. Radiological features of low vascularization and the absence of 


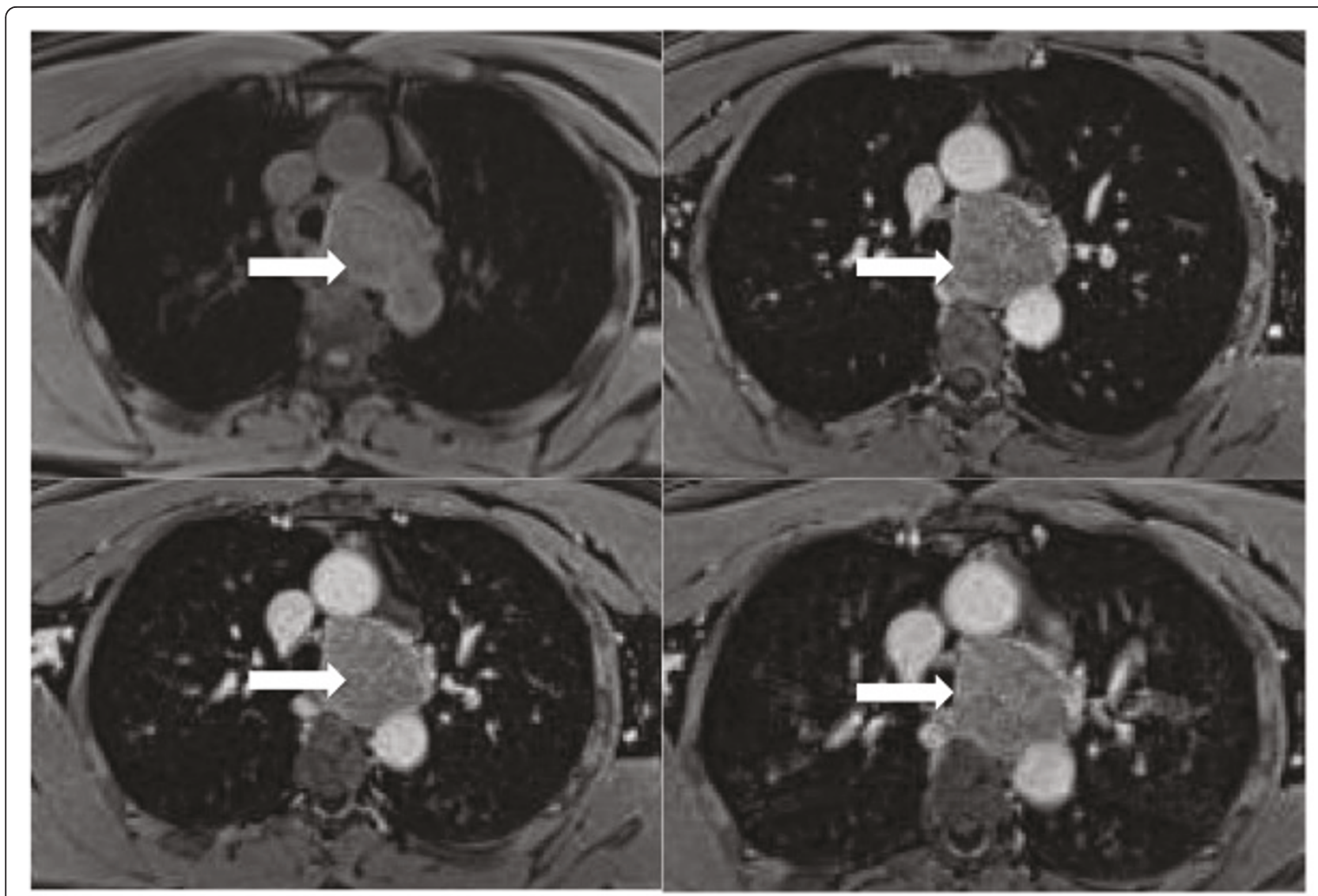

Figure 2 T1-weighted volumetric interpolated breath-hold examination (VIBE) sequences on axial planes. The post-contrast T1-weighted images show poor enhancement within the solid lesion (white arrows).

involvement of the vascular and biliary structures shown by the hepatic and mediastinal lesions led to a first diagnostic hypothesis of mediastinal lymphoma with hepatic spread. The latter hypothesis was also supported by the fact that more than $80 \%$ of patients with Hodgkin's disease and almost $45 \%$ of patients with non-Hodgkin's lymphoma show intrathoracic involvement $[7,8]$. Moreover, in the thorax, lymphoma frequently involves the anterior mediastinal and paratracheal regions [9]. However, due to the absence of systemic symptoms and the presence of extrathoracic involvement at presentation, which usually occurs in immunocompromised patients, bioptical sampling of the hepatic lesions was performed and revealed the presence of a neuroendocrine malignancy.

A multimodality approach is optimal for detecting the primary tumor and metastases and can include multidetector computed tomography (CT), functional imaging, MRI, ultrasonography, endoscopy, digital subtraction angiography and venous sampling.

For the evaluation of liver metastases, the use of triple-phase multidetector $\mathrm{CT}$ and contrast material- enhanced MRI is suggested to establish a baseline, which can help assess disease extent and allow posttreatment comparison. The arterial anatomy of the liver and portal vein patency can also be determined. Liver metastases have low signal intensity on T1-weighted MRI and high signal intensity on T2-weighted images [10].

The treatment of patients with liver metastases is complex, and there are often several factors that must be taken into account. Curative surgery should always be considered but is rarely possible due to the diffuse nature of the disease.

NETs are relatively slow-growing tumors; therefore, patients can survive for several years with current treatment strategies. Interventional radiology has played an increasingly important role.

Interventional radiologists could approach liver metastases by performing procedures such as embolization, chemoembolization, targeted radionuclide therapy and local ablative techniques (radiofrequency ablation, cryotherapy and percutaneous ethanol injection) [11]. Radiological treatments may be combined 


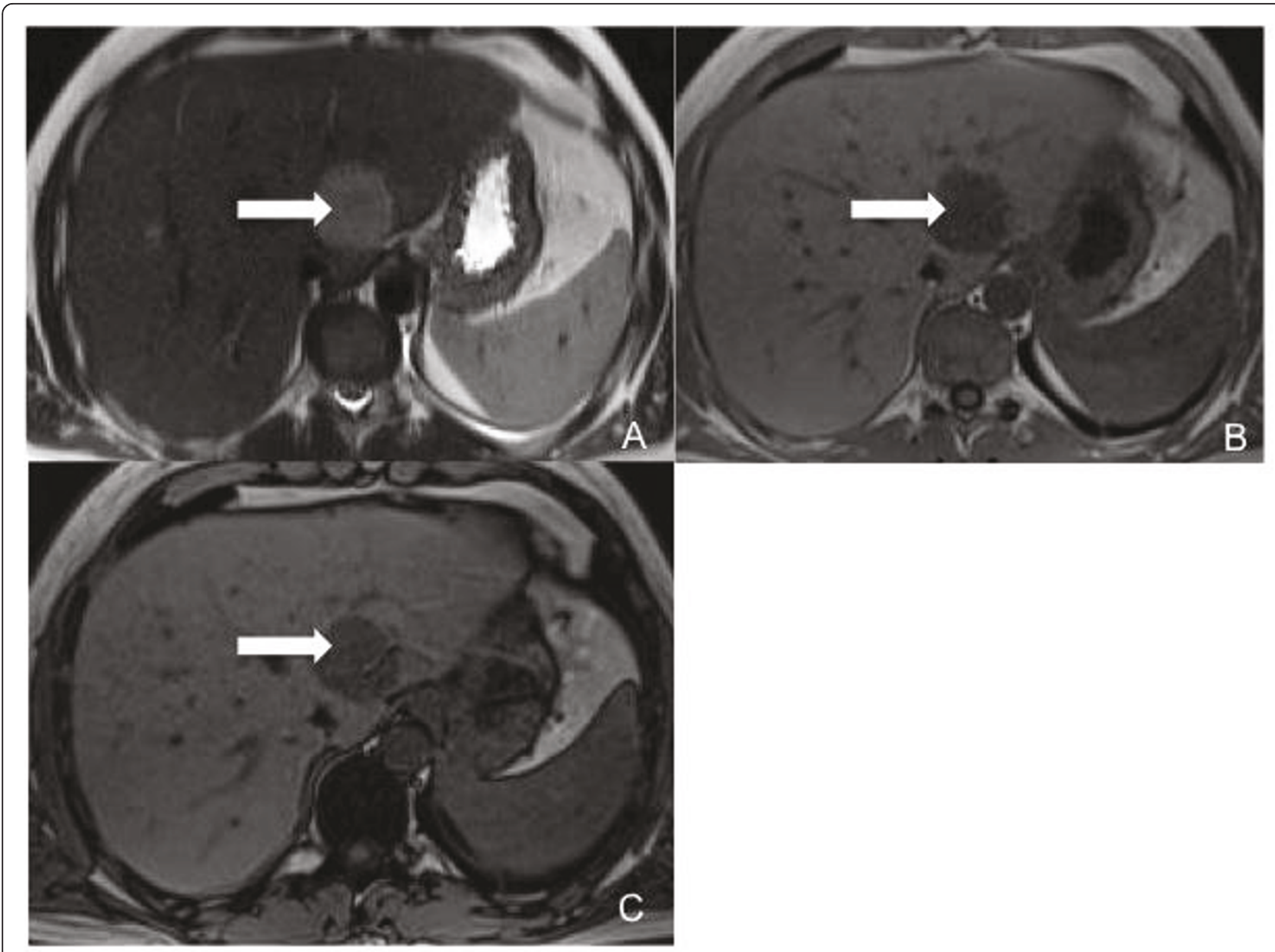

Figure 3 T2-weighted HASTE sequence on axial plane. Shows one of the solid liver lesions in the II segment, with the same patterns of signal intensity showed by the mediastinal mass on the (A) T2-weighted and ( $B, C$ ) T1-weighted images before contrast median injection (white arrows).

with curative surgery, which should always be considered as a treatment option. Chemoembolization should not be performed in patients in whom portal vein obstruction, liver insufficiency, abscess, previous biliary anastomoses and biliary obstruction have been discovered during the diagnostic phase. Whether chemoembolization should be used rather than embolization is still a matter of debate, since recent evidence has emerged that the addition of intraarterial chemotherapy to embolization does not improve the outcome in patients with carcinoid tumors [12]. Radionuclide therapy could be proposed if other treatments are not possible or have failed; positive uptake of ${ }^{111} \mathrm{In}$ pentetreotide has been proven on a previous scintigraphy and trained staff is available. Radionuclide therapy should not be performed in cases of pregnancy and lactation, or bone marrow dysfunction (hemoglobin below $10 \mathrm{~g} / \mathrm{dL}$, white blood cell count fewer than $2 \times$
$10^{3} / \mathrm{mL}$, platelet count below $100 / \mathrm{mL}$ ) [13]. Ablative therapies should be performed as adjuncts to surgical resection, for treatment of patients with unresectable tumor, palliation and recurrence after surgical resection or prior ablation $[14,15]$.

\section{Conclusion}

Mediastinal neuroendocrine tumors are a challenging disease for clinicians and radiologists. Although the clinical approach is still the mainstay both in the diagnostic and therapeutic phases, the radiological approach could provide valuable support. The differential diagnosis in patients with mediastinal masses and liver lesions should include neuroendocrine tumor.

\section{Consent}

Written informed consent was obtained from the patient for publication of this case report and any accompanying 


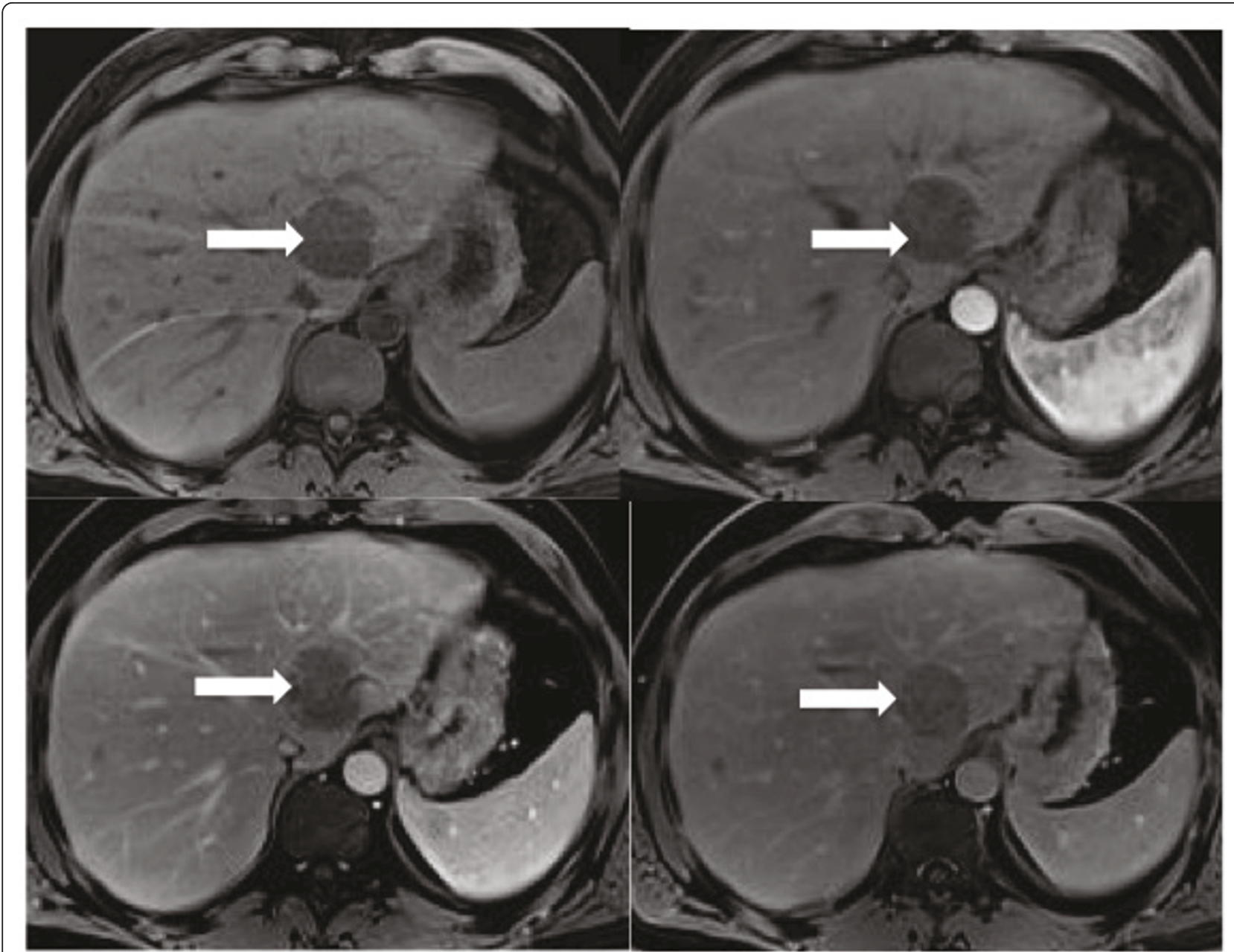

Figure 4 T1-weighted VIBE sequences obtained before and after contrast median injection showed a poor enhancement within the solid lesions (white arrows).

images. A copy of the written consent is available for review by the Editor-in-Chief of this journal.

\section{Author details}

'Department of Radiology, Campus Bio-Medico, University of Rome, Italy. ${ }^{2}$ Department of Oncology, Campus Bio-Medico, University of Rome, Italy.

\section{Authors' contributions}

BV, FDG and SB analyzed and interpreted the patient data. RDV, RFG and BBZ performed the thorax and abdominal magnetic resonance. RDV and GC were major contributors in writing the manuscript. All authors read and approved the final manuscript.

\section{Competing interests}

The authors declare that they have no competing interests.

Received: 9 March 2011 Accepted: 5 October 2011

Published: 5 October 2011

\section{References}

1. Strollo DC, de Christenson MLR, Jett JR: Primary mediastinal tumours. Part II. Tumors of the middle and posterior mediastinum. Chest 1997,

112(5):1344-1357.
2. Duwe BV, Sterman DH, Musani Al: Tumors of the Mediastinum. Chest 2005, 128(4):2893-2909.

3. Crapo JD, Glassroth J, Karlinsky J, King TE Jr: Baum's textbook of pulmonary diseases Philadelphia, PA: Lippincott Williams \& Wilkins; 2004, 883-912.

4. Macchiarini $\mathrm{P}$, Ostertag $\mathrm{H}$ : Uncommon primary mediastinal tumours. Lancet Oncol 2004, 5(2):107-118.

5. Steward MJ, Warbey VS, Malhotra A, Caplin ME, Buscombe JR, Yu D: Neuroendocrine tumors: role of interventional radiology in therapy. Radiographics 2008, 28(4):1131-1145

6. Socia E, Kloppel G, Sobin $\mathrm{LH}$, et al: Histologic typing of endocrine tumors. WHO international histological classification of tumors Heidelberg, Germany: Springer Verlag; 2000.

7. Castellino RA, Blank N, Hoppe RT, Cho C: Hodgkin disease: contributions of chest CT in the initial staging evaluation. Radiology 1986, 160(3):603-605.

8. Castellino RA, Hilton S, O'Brien JP, Portlock CS: Non-Hodgkin lymphoma: contribution of chest CT in the initial staging evaluation. Radiology 1996, 199(1):129-132.

9. Sharma A, Fidias P, Hayman LA, Loomis SL, Taber KH, Aquino SL: Patterns of lymphadenopathy in thoracic malignancies. Radiographics 2004 24(2):419-434.

10. Dromain C, de Baere T, Lumbroso J, Caillet H, Laplanche A, Boige V, Ducreux M, Duvillard P, Elias D, Schlumberger M, Sigal R, Baudin E: Detection of liver metastases from endocrine tumors: a prospective comparison of somatostatin receptor scintigraphy, computed 
tomography, and magnetic resonance imaging. J Clin Oncol 2005, 23(1):70-78.

11. McStay MK, Maudgil D, Williams M, Tibballs JM, Watkinson AF, Caplin ME, Buscombe JR: Large volume liver metastases from neuroendocrine tumors: hepatic intraarterial 90Y-DOTA-lanreotide as effective palliative therapy. Radiology 2005, 237(2):718-726.

12. Gupta S, Johnson MM, Murthy R, Ahrar K, Wallace MJ, Madoff DC, McRae SE, Hicks ME, Rao S, Vauthey JN, Ajani JA, Yao JC: Hepatic arterial embolization and chemoembolization for the treatment of patients with metastatic neuroendocrine tumors: variables affecting response rates and survival. Cancer 2005, 104(8):1590-1602.

13. Steward MJ, Warbey VS, Malhotra A, Caplin ME, Buscombe JR, Yu D: Neuroendocrine tumors: role of interventional radiology in therapy. Radiographics 2008, 28(4):1131-1145.

14. Atwell TD, Charboneau JW, Que FG, Rubin J, Lewis BD, Nagorney DM, Callstrom MR, Farrell MA, Pitot HC, Hobday TJ: Treatment of neuroendocrine cancer metastatic to the liver: the role of ablative techniques. Cardiovasc Intervent Radiol 2005, 28(4):409-421.

15. Shetty PK, Baliga SV, Balaiah K, Bnana PS: Primary hepatic neuroendocrine tumor: an unusual cystic presentation. Indian J Path Microbiol 2010, 53(4):760-762.

doi:10.1186/1752-1947-5-506

Cite this article as: Del Vescovo et al:: Neuroendocrine tumor presenting like lymphoma: a case report. Journal of Medical Case Reports 2011 5:506.

\section{Submit your next manuscript to BioMed Central} and take full advantage of:

- Convenient online submission

- Thorough peer review

- No space constraints or color figure charges

- Immediate publication on acceptance

- Inclusion in PubMed, CAS, Scopus and Google Scholar

- Research which is freely available for redistribution

Submit your manuscript at www.biomedcentral.com/submit 